\title{
Correlates of Walking for Transportation and Use of Public Transportation Among Adults in St Louis, Missouri, 2012
}

Marissa L. Zwald, MPH; James A. Hipp, PhD; Marui W. Corseuil, MPH; Elizabeth A. Dodson, $\mathrm{PhD}, \mathrm{MPH}$

Suggested citation for this article: Zwald ML, Hipp JA, Corseuil MW, Dodson EA. Correlates of Walking for Transportation and Use of Public Transportation Among Adults in St Louis, Missouri, 2012. Prev Chronic Dis 2014;11:140125. DOI: http://dx.doi.org/10.5888/pcd11.140125圈.

PEER REVIEWED

\section{Abstract}

\section{Introduction}

Attributes of the built environment can influence active transportation, including use of public transportation. However, the relationship between perceptions of the built environment and use of public transportation deserves further attention. The objectives of this study were 1) to assess the relationship between personal characteristics and public transportation use with meeting national recommendations for moderate physical activity through walking for transportation and 2) to examine associations between personal and perceived environmental factors and frequency of public transportation use.

\section{Methods}

In 2012, we administered a mail-based survey to 772 adults in St Louis, Missouri, to assess perceptions of the built environment, physical activity, and transportation behaviors. The abbreviated International Physical Activity Questionnaire was used to assess walking for transportation and use of public transportation. The Neighborhood Environment Walkability Scale was used to examine perceptions of the built environment. Associations were assessed by using multinomial logistic regression.

\section{Results}

People who used public transportation at least once in the previous week were more likely to meet moderate physical activity recommendations by walking for transportation. Age and employment were significantly associated with public transportation use. Perceptions of high traffic speed and high crime were negatively associated with public transportation use.

\section{Conclusion}

Our results were consistent with previous research suggesting that public transportation use is related to walking for transportation. More importantly, our study suggests that perceptions of traffic speed and crime are related to frequency of public transportation use. Future interventions to encourage public transportation use should consider policy and planning decisions that reduce traffic speed and improve safety.

\section{Introduction}

Regular physical activity is essential to overall health. It is associated with weight control; reduced risk of many chronic diseases such as coronary heart disease, stroke, diabetes, hypertension, colon cancer, breast cancer, and depression; and the prevention of early death $(1,2)$. Despite the well-established health benefits of regular physical activity, fewer than half of US adults meet the recommended levels of physical activity outlined in the 2008 Physical Activity Guidelines for Americans, to engage in at least 150 minutes of moderate-intensity aerobic activity each week $(1,3)$. 
Walking for transportation, which can include walking at the beginning or end of a trip taken by public transportation, can provide opportunities for meeting recommended levels of physical activity. Previous studies have demonstrated that people who walk to and from public transportation stops engage in more daily physical activity than those who do not (4-9). Rissel and colleagues (10) recently reviewed 9 public transportation and physical activity studies and found that although these studies used different measures of physical activity, public transportation use was associated with at least 8 additional minutes of daily physical activity, with some studies reporting a range of 12 to 15 additional minutes (10). More evidence is needed, however, to understand the association between public transportation use and physical activity and, more specifically, the built environment features that may influence this relationship (8).

The association between walking for transportation and objectively measured attributes of the built environment, such as residential density, land use mix, street connectivity, and accessibility to destinations, is well-documented (11-15). A recent study by Wasfi and colleagues (16) examined the relationship between objectively measured characteristics of the built environment, including residential density, land use mix, and street connectivity, and walking to public transportation; contrary to the aforementioned studies (11-15), the investigators found no significant associations. Moreover, a growing body of evidence has also suggested that perceptions of built environment characteristics can influence transportation-related physical activity, including walking for transportation. Some of these perceived environmental factors include perceived personal safety from crime and traffic, accessibility to walking and bicycling facilities, aesthetics, residential density, land use mix, and street connectivity $(11,15,17-19)$. However, little is known about how perceptions of the built environment influence public transportation use. Although communities that support walking for transportation tend to also encourage public transportation use (8), understanding the perceived environmental factors specifically related to public transportation use could inform improved policy and planning decisions on the built environment and public transit systems.

Our study had 2 objectives. The first was to further assess the relationship between personal characteristics and use of public transportation and walking for transportation. The second objective was to examine associations between personal and perceived environmental factors with frequency of public transportation use.

\section{Methods \\ Study setting}

This study was conducted in St. Louis, Missouri, from July through December 2012. In 2012, St. Louis had an area of 62 square miles and a population of 318,172 , of which approximately $52 \%$ were female, $79 \%$ were aged 18 years or older, $16 \%$ had a total household income less than $\$ 10$,ooo per year, and $56 \%$ were employed outside of the home (20). The public transportation system in St. Louis is operated by Metro St. Louis, which at the time of data collection offered bus services with 75 different routes, a light rail train system serving 37 stations in the greater St. Louis area, and call-a-ride shuttles for people with disabilities. Metro St. Louis offered reduced-fare programs for seniors $(\geq 65 \mathrm{y})$ and persons with disabilities (21).

Our study was part of a broader investigation of neighborhood conditions, physical activity, transportation behaviors, and personal characteristics that was approved by the institutional review board of Washington University in St. Louis. We used simple random sampling to administer a mail-based survey to 2,898 households in St. Louis (refers throughout this article to the city of St. Louis only and not to St. Louis County). An adult aged 18 years or older who resided at the address to which the survey was mailed was instructed to complete the survey, and only 1 survey per household was considered for the study. A total of 772 surveys were collected, an overall response rate of $26.6 \%$.

\section{Measures}

Dependent variables

The International Physical Activity Questionnaire (IPAQ), long-form, was used to measure walking for transportation and public transportation use in the past 7 days. Walking for transportation was categorized according to the most recent United States Physical Activity Guidelines for duration of moderate physical activity (22). The 3 response categories for this variable were 1) met national guidelines for moderate physical activity by walking for transportation ( $\geq 150 \mathrm{~min} / \mathrm{wk}$ ); 2) engaged in some walking for transportation but did not meet national guidelines (1-149 min/wk); or 3) engaged in no walking for transportation (o min/wk) (1). To understand differences across regular transit users, occasional transit users, and transit nonusers, the number of days traveled by bus or train in the previous week was categorized as 5 or more days per week, 1 to 4 days per week, or o days per week. The International Physical Activity Questionnaire has been previously validated (22).

Independent variables

The following individual factors were included in the analysis: sex, age (18-29 y, 30-39 y, 40-49 y, 50-59 y, $\geq 60$ y), annual household income level $(<\$ 10,000, \$ 10,000-\$ 29,999, \$ 30,000-\$ 49,999, \$ 50,000-\$ 69,999, \geq \$ 70,000)$, and employment status (employed or unemployed). 
To assess perceptions of built environment characteristics, items from the abbreviated version of the Neighborhood Environment Walkability Scale (NEWS) were selected by analyzing previous research and by including variables hypothesized to influence public transportation use (11-19,23). A previous study conducted by Adams et al. demonstrated good concurrent validity for self-reported built environment items included in NEWS with objective Geographic Information System measures (24). For the current study, 4 items were used to assess perceptions of traffic safety: 1) traffic volume, 2) traffic speed, 3) presence of crosswalks and pedestrian signals, and 4) visibility of pedestrians and bicyclists. Four items were used to measure perceptions of personal safety: 1) perceived nearby crime, 2) safety from crime when walking during the day, 3) safety from crime when walking at night, and 4) street lighting at night. One item was used to assess perceptions of accessibility to sidewalks. These 9 NEWS items were measured by using 4-point Likert-scale-type questions (strongly agree to strongly disagree). The response categories were dichotomized (agree vs disagree).

Perceived accessibility to neighborhood destinations was assessed by using NEWS items that asked participants to report the number of minutes required to walk from the participant's home to the nearest of 20 specific businesses or facilities, such as a supermarket, post office, or coffee shop. The 20 items were collapsed into a single destinations measure representing the number of destinations within a 10-minute walk. Responses were categorized as 0 destination, 1 to 5 destinations, 6 to 10 destinations, and 11 or more destinations.

Statistical analysis

Descriptive statistics and frequencies were used to describe individual participant characteristics, frequency of participants meeting national recommendations for moderate physical activity by walking for transportation, and frequency of public transportation use. Bivariate associations between each personal characteristic and public transportation use with the dependent variable of walking for transportation were evaluated by using multinomial logistic regression to estimate the odds ratios (ORs) and 95\% confidence intervals (CIs). To create more parsimonious models, only those characteristics with a value of $P \leq .20$ by Wald's test in the bivariate associations were included in the final analysis examining the associations between categories of minutes spent walking for transportation (25). The reference category was respondents who reported not walking for transportation in the previous week. $P \leq .05$ was considered statistically significant in the final model.

To assess correlates of public transportation use, the analysis steps described above were used, including personal and perceived built environment characteristics as independent variables and frequency of public transportation use as the dependent variable. The reference category was transit nonuser. All analyses were performed using Stata version 12.0 (STATA Corp, College Station, Texas).

\section{Results}

\section{Description of the sample}

Compared with the demographic composition of St. Louis at the time of our study (20), our sample had a higher proportion of female participants (64\%) and a higher percentage of respondents who earned less than $\$ 10,000$ per year (27\%), but our sample was similarly represented across other individual characteristics assessed (Table 1). The majority of the sample (57\%) was employed outside the home, and most participants were younger than 50 years (58\%).

Approximately one-third of the sample had not walked for transportation in the previous week (34\%), whereas $35 \%$ of the sample reported walking for transportation from 1 to 149 minutes in the previous week and $31 \%$ for more than 150 minutes in the previous week. Overall, $70 \%$ of participants reported they had not used public transportation in the previous week.

\section{Individual and public transportation correlates of walking for transportation}

Table 2 summarizes the associations between personal characteristics and public transportation use with minutes spent walking for transportation in the previous week. The odds of meeting moderate physical activity guidelines by walking for transportation (OR, 2.08; CI, 1.27-3.42) and walking for transportation but not meeting the guidelines (OR, 2.11; CI, 1.31-3.40) were higher for participants who reported some public transportation use than for participants who did not use public transportation. Compared with participants who did not use public transportation, those who used public transportation for 5 or more days in the previous week were 8.61 times more likely to meet moderate physical activity guidelines by walking for transportation (CI, 3.87-19.20) and 3.47 times more likely to walk for transportation but not meet moderate physical activity guidelines ( CI, 1.47-8.19).

\section{Individual and perceived environmental correlates of public transportation use}

Table 3 presents the associations between personal characteristics and perceived environmental factors with frequency categories of public transportation use in the previous week. The odds of using public transportation more than once a 
week (1-4 days/previous week) were significantly greater among participants aged 50 to 59 years (OR, 1.98; CI, 1.063.70) than among participants aged 18 to 29 years. Adults older than 60 were significantly less likely to have used public transportation 5 or more days in the previous week (OR, 0.34; CI, 0.14-0.86) than participants aged 18 to 29. Among other individual factors examined, employed participants were significantly less likely than unemployed participants to have used public transportation at least once in the previous week (1-4 days/previous wk) (OR, 0.56; CI, 0.35-0.92). This relationship differed for frequent public transportation use: the likelihood of having used public transportation 5 or more days in the previous week was significantly greater among employed participants than among the unemployed (OR, 2.99; CI, 1.52-5.90). For each income category examined, participants with higher incomes were significantly less likely to have used public transportation 1 to 4 days in the previous week than those with an annual income less than $\$ 10,000$. Similarly, compared with participants earning less than $\$ 10,000$ per year, participants with higher incomes were less likely to have used public transportation 5 or more days in the past week.

Among the perceived environmental factors assessed, the volume of traffic, presence of crosswalks and pedestrian signals, visibility of pedestrians and bicyclists, and street lighting at night were not significantly associated with public transportation use and were not included in the final, parsimonious model. Participants who reported that traffic exceeded the posted speed limits in their neighborhood were significantly less likely to have used public transportation for 1 to 4 days in the previous week (OR, 0.54; CI, 0.36-0.81) than those who did not report high traffic speeds in their neighborhood. Participants who perceived high crime in their neighborhood had significantly lower odds of having used public transportation for more than 5 days in the previous week (OR, 0.50; CI, 0.28-0.87) than those who did not report high crime. No significant associations were found for safety from crime when walking during the day, safety from crime when walking at night, accessibility of sidewalks, or accessibility of destinations.

\section{Discussion}

Our study found that St. Louis adults who used public transportation were more likely to meet moderate physical activity recommendations by walking for transportation. Our findings are consistent with earlier research demonstrating that regular public transportation use is associated with increased physical activity $(4-10,16,26)$. Therefore, public health efforts to support public transportation use may not only reduce traffic congestion, air pollution, and noise pollution in communities, but also may help people meet recommended levels of moderate physical activity (27).

Of the personal characteristics assessed in our study, age, employment, and income level were significantly associated with public transportation use. One key finding was that persons aged 6o years or older were less likely to use public transportation. As older adults often face mobility challenges, built environment features can accommodate this population, including bus shelters with seating, improved lighting, signage, and crosswalk signals that allow for slower walking speeds. The relationship between these types of built environment and transportation attributes with public transportation use among older adults is a topic for future investigation. Consistent with previous transportation research (28), our results showed that people with higher incomes were less likely to use public transportation. Because public transit may be the sole mode of transportation for lower-income people, future studies should examine the relationship in this population subgroup between perceptions of affordability and accessibility of public transportation with public transit use and with walking for transportation.

Our study builds on past research that has examined the relationship between perceptions of the built environment and walking for transportation (11-19) by assessing the specific, perceived environmental factors related to public transportation use. Our findings indicate that perceptions of high traffic speed and high crime were negatively associated with frequency of public transportation use. Previous transportation studies have examined the relationship between perceived and objective measures of crime nearby transit stops with bus and rail ridership and have suggested that the perception of high crime is a factor that can discourage public transit use (28-31). Loukaitou-Sideris and colleagues (29) found that crime at transit stops was higher where transit stops had poor environmental attributes, including graffiti, litter, or close proximity to undesirable establishments such as liquor stores or vacant buildings. In the same study, positive environmental characteristics, such as the presence of bus shelters and good visibility, were associated with lower crime at transit stops (29). These findings, along with those of our study, demonstrate the importance of future programs, policies, and infrastructure changes aimed at increasing public transportation use to improve perceived and actual safety from both crime and traffic. These types of investments, supportive of public transportation in St. Louis and in similar urban communities, could thereby increase walking for transportation.

Our study has several limitations. Our findings are based on cross-sectional data; thus, no causal relationships could be established. Although valid and reliable instruments were used, including the IPAQ and NEWS, data were collected via a self-administered questionnaire, and reporting biases may have occurred. Selection bias may have been introduced because of a low response rate; however, our response rate is similar to those of other studies on physical activity and transportation behaviors (15,32). In addition, we did not assess the intensity levels of the physical activity achieved by walking for transportation among this study sample. Finally, we did not explore the potential impact of certain transit service characteristics on public transportation use, including level of satisfaction with services 
associated with the public transportation system, type of public transportation service used, proximity to a public transportation stop, length of the public transportation trip, or the number of transfers taken on a typical trip. Future research should examine how these transit service characteristics may influence public transportation use and walking for transportation.

Despite these limitations, our results strengthen the evidence base demonstrating that public transportation use can support people in meeting moderate physical activity recommendations by walking for transportation $(4-10,33)$. Our study also contributes to the limited body of existing literature regarding perceived environmental factors and public transportation use. We found that perceived environmental factors of traffic speed and neighborhood crime were negatively correlated with public transportation use in St. Louis. Public health and transportation professionals in St. Louis and elsewhere who want to encourage public transit use should implement strategies to decrease traffic speed on roadways through traffic calming, lowering speed limits, and increasing enforcement of traffic speed. Transportation planners and engineers should explore opportunities to enhance personal safety features on buses and trains and near transit stops to create safe environments for people using public transit. Public health and transportation professionals should also collaborate with law enforcement officials to increase police presence near bus and train stops. These changes have the potential to improve public transportation systems, which can provide more opportunities for people to meet recommended levels of physical activity and to achieve positive health outcomes.

\section{Acknowledgments}

This study was supported by the International Center for Advanced Renewable Energy and Sustainability at Washington University in St. Louis, Missouri and the Johns Hopkins Global Center on Childhood Obesity (no. 2001656847). We thank the study participants for their cooperation and Leslie Duling and Nora Geary for their help in study coordination, data collection, and data management.

\section{Author Information}

Corresponding Author: Marissa L. Zwald, MPH, Prevention Research Center in St Louis, Brown School, Washington University in St Louis, 621 N Skinker Blvd, Campus Box 1006, St Louis, MO 63130. Telephone: 314-935-0164. E-mail: MZwald@wustl.edu.

Author Affiliations: James A. Hipp, Elizabeth A. Dodson, Brown School, Washington University in St Louis, St Louis, Missouri; Marui W. Corseuil, Federal University of Santa Catarina, Santa Catarina, Brazil.

\section{References}

1. United States Department of Health and Human Services. 2008 physical activity guidelines for Americans; 2008. http:// www.health.gov/paguidelines/pdf/paguide.pdf. Accessed June 30, 2013.

2. World Health Organization. Global recommendations on physical activity for health. http://whqlibdoc.who.int/publications/2010/9789241599979_eng.pdf?ua=1. Accessed January 30, 2014.

3. Schiller JS, Lucas JW, Ward BW, Peregoy JA. Summary health statistics for US adults: National Health Interview Survey, 2010. Vital Health Stat 10 ;2012(252):1-207. PubMed 圈

4. Besser LM, Dannenberg AL. Walking to public transit: steps to help meet physical activity recommendations. Am J Prev Med 2005;29(4):273-80. CrossRef 圈 PubMed 圈

5. Frank LD, Greenwald MJ, Winkelman S, Chapman J, Kavage S. Carbonless footprints: promoting health and climate stabilization through active transportation. Prev Med 2010;50(Suppl 1):S99-105. CrossRef 国 PubMed 国

6. Freeland AL, Banerjee SN, Dannenberg AL, Wendel AM. Walking associated with public transit: moving toward increased physical activity in the United States. Am J Public Health 2013;103(3):536-42. CrossRef 圈 PubMed 圈

7. Lachapelle U, Frank L. Transit and health: mode of transport, employer-sponsored public transit pass programs, and physical activity. J Public Health Policy 2009;30(Suppl 1):S73-94. CrossRef 国 PubMed 圈

8. Lachapelle U, Frank L, Saelens BE, Sallis JF, Conway TL. Commuting by public transit and physical activity: where you live, where you work, and how you get there. J Phys Act Health 2011;8(Suppl 1):S72-82. PubMed 圈

9. Wener RE, Evans GW. A morning stroll: levels of physical activity in car and mass transit commuting. Environ Behav 2007;39(1):62-74. CrossRef 圈

10. Rissel C, Curac N, Greenaway M, Bauman A. Physical activity associated with public transport use - a review and modeling of potential benefits. Int J Environ Res Public Health 2012;9(7):2454-78. CrossRef 国 PubMed 圈

11. Bauman AE, Reis RS, Sallis JF, Wells JC, Loos RJF, Martin BW. Correlates of physical activity: why are some people physically active and others not? Lancet 2012;380(9838):258-71. CrossRef $⿴ 囗 0)$ PubMed 国 
12. Lee C, Moudon AV. Correlates of walking for transportation or recreation purposes. J Phys Act Health 2006;3 (Suppl 1):77-98.

13. Owen N, Humpel N, Leslie E, Bauman A, Sallis JF. Understanding environmental influences on walking: review and research agenda. Am J Prev Med 2004;27(1):67-76. CrossRef 国 PubMed 圈

14. Saelens BE, Handy SL. Built environment correlates of walking: a review. Med Sci Sports Exerc 2008;40(Suppl 7):S550-66. CrossRef 圈 PubMed 圈

15. Van Dyck D, Cerin E, Conway TL, De Bourdeaudhuij I, Owen N, Kerr J, et al. Perceived neighborhood environmental attributes associated with adults' transport-related walking and cycling: Findings from the USA, Australia and Belgium. Int J Behav Nutr Phys Act 2012;9:(70)1-14. CrossRef 圈 PubMed 圈

16. Wasfi RA, Ross NA, El-Geneidy AM. Achieving recommended daily physical activity levels through commuting by public transportation: unpacking individual and contextual influences. Health Place 2013;23:18-25. CrossRef 园 PubMed 国

17. Duncan MJ, Spence JC, Mummery WK. Perceived environment and physical activity: a meta-analysis of selected environmental characteristics. Int J Behav Nutr Phys Act 2005;2(11):1-9. CrossRef 圈 PubMed 国

18. Parra DC, Hoehner CM, Hallal PC, Ribeiro IC, Reis R, Brownson RC, et al. Perceived environmental correlates of physical activity for leisure and transportation in Curitiba, Brazil. Prev Med 2011;52(3-4):234-8. PubMed 圈

19. Kaczynski AT. Neighborhood walkability perceptions: associations with amount of neighborhood-based physical activity by intensity and purpose. J Phys Act Health 2010;7(1):3-10. PubMed 国

20. United States Census Bureau. St. Louis City, Missouri, state and county QuickFacts; 2014. http://factfinder2.census.gov/faces/nav/jsf/pages/community_facts.xhtml. Accessed January 30, 2014.

21. Metro Transit St. Louis. http://www.metrostlouis.org/About/Overview.aspx. Accessed January 30, 2104.

22. Craig CL, Marshall AL, Sjöström M, Bauman AE, Booth ML, Ainsworth BE, et al. International physical activity questionnaire: 12-country reliability and validity. Med Sci Sports Exerc 2003;35(8):1381-95. CrossRef 圈 PubMed 国

23. Saelens BE, Sallis JF, Black JB, Chen D. Neighborhood-based differences in physical activity: an environment scale evaluation. Am J Public Health 2003;93(9):1552-8. CrossRef 圈 PubMed 圈

24. Adams MA, Ryan S, Kerr J, Sallis JF, Patrick K, Frank LD, et al. Validation of the Neighborhood Environment Walkability Scale (NEWS) items using geographic information systems. J Phys Act Health 2009;6(1):S113-23. PubMed 圈

25. Maldonado G, Greenland S. Simulation study of confounder-selection strategies. Am J Epidemiol 1993;138 (11):923-36. PubMed 圈

26. Villanueva K, Giles-Corti B, McCormack G. Achieving 10,000 steps: a comparison of public transport users and drivers in a university setting. Prev Med 2008;47(3):338-41. CrossRef 圈 PubMed 因

27. Litman T. Transportation and public health. Annu Rev Public Health 2013;34:217-33. CrossRef 国 PubMed 国

28. Kim S, Ulfarsson GF, Hennessy JT. Analysis of light rail rider travel behavior: impacts of individual, built environment, and crime characteristics on transit access. Transport Res A 2008;47(3):338-41.

29. Loukaitou-Sideris A, Liggett R, Iseki H, Thurlow W. Measuring effects of built environment on bus stop crime. Environ Plann B 2001;28(2):255-80. CrossRef 圈

30. Loukaitou-Sideris A, Liggett R, Iseki H. The geography of transit crime: Documentation and evaluation of crime incidence on and around the green line stations in Los Angeles. J Plann Educ Res 2002;22:135-51. CrossRef 圈

31. Liggett R, Loukaitou-Sideris A, Iseki H. Bus stop environmental connection: do characteristics of the built environment correlate with bus stop crime? Transport Res Rec 2001;1760(1):20-7.

32. Bopp M, Kaczynski AT, Campbell ME. Health related factors associated with mode of travel to work. J Environ Pub Health 2013;2013:1-9. PubMed 圈

33. Saelens BE, Moudon AV, Kang B, Hurvitz PM, Zhou C. Relation between higher physical activity and public transit use. Am J Public Health 2014;104(5):854-9. CrossRef 圈 PubMed 圈

\section{Tables}

Table 1. Participant $(\mathrm{N}=772)$ Characteristics, Survey of Transportation Use, St. Louis, Missouri, 2012 
Preventing Chronic Disease | Correlates of Walking for Transportation and Use of Public ... Page 7 of 10

\begin{tabular}{|c|c|}
\hline Characteristic & $\%(n)^{a}$ \\
\hline \multicolumn{2}{|l|}{ Sex } \\
\hline Male & $36.4(275)$ \\
\hline Female & $63.6(480)$ \\
\hline \multicolumn{2}{|l|}{ Age, y } \\
\hline $18-29$ & $16.8(127)$ \\
\hline $30-39$ & $22.6(171)$ \\
\hline $40-49$ & $18.6(141)$ \\
\hline $50-59$ & $19.1(145)$ \\
\hline$\geq 60$ or over & $23.0(174)$ \\
\hline \multicolumn{2}{|l|}{ Income, \$ } \\
\hline$<10,000$ & $27.0(202)$ \\
\hline $10,000-29,999$ & $24.3(182)$ \\
\hline $30,000-49,000$ & $16.4(123)$ \\
\hline $50,000-69,000$ & $11.6(87)$ \\
\hline$\geq 70,000$ & $20.6(154)$ \\
\hline \multicolumn{2}{|c|}{ Employment status } \\
\hline Unemployed & $42.9(331)$ \\
\hline Employed & $57.1(440)$ \\
\hline \multicolumn{2}{|c|}{ Minutes walked in preceding week } \\
\hline 0 & $34.3(263)$ \\
\hline $1-149$ & $34.7(266)$ \\
\hline$\geq 150$ & $31.0(238)$ \\
\hline \multicolumn{2}{|c|}{ No. days used public transportation in preceding week } \\
\hline 0 & $70.3(539)$ \\
\hline $1-4$ & $19.9(153)$ \\
\hline$\geq 5$ & $9.8(75)$ \\
\hline
\end{tabular}

a Categories do not total 772 because of missing responses.

Table 2. Relationship Between Personal Characteristics and Public

Transportation Use With Walking for Transportation Among Adults ( $\mathrm{N}=$ 772 ) in St. Louis, Missouri, 2012

\begin{tabular}{|c|c|c|}
\hline \multirow[b]{3}{*}{ Personal Characteristic and Public Transportation Use } & \multicolumn{2}{|c|}{ Walking for Transportation } \\
\hline & 1-149 Minutes/Week & $\geq 150$ Minutes/Week \\
\hline & OR (95\% CI) & OR $(95 \% \mathrm{CI})$ \\
\hline \multicolumn{3}{|l|}{ Personal characteristic } \\
\hline \multicolumn{3}{|l|}{ Sex } \\
\hline Male & 1 [Reference] & 1 [Reference] \\
\hline Female & $1.09(0.75-1.57)$ & $1.14(0.77-1.68)$ \\
\hline
\end{tabular}


Preventing Chronic Disease | Correlates of Walking for Transportation and Use of Public ... Page 8 of 10

\begin{tabular}{|c|c|c|}
\hline \multirow[b]{3}{*}{ Personal Characteristic and Public Transportation Use } & \multicolumn{2}{|c|}{ Walking for Transportation } \\
\hline & 1-149 Minutes/Week & $\geq 150$ Minutes/Week \\
\hline & OR $(95 \% \mathrm{CI})$ & OR (95\% CI) \\
\hline $18-29$ & 1 [Reference] & 1 [Reference \\
\hline $30-39$ & $0.84(0.47-1.50)$ & $0.54(0.30-0.97$ \\
\hline $40-49$ & $0.79(0.43-1.45)$ & $0.61(0.33-1.13$ \\
\hline $50-59$ & $0.70(0.38-1.31)$ & $0.83(0.46-1.52$ \\
\hline$\geq 60$ & $0.86(0.47-1.58)$ & $0.64(0.34-1.19$ \\
\hline \multicolumn{3}{|l|}{ Income, \$ } \\
\hline$<10,000$ & 1 [Reference] & 1 [Reference \\
\hline $10,000-29,999$ & $1.15(0.67-1.96)$ & $1.10(0.66-1.83$ \\
\hline $30,000-49,999$ & $1.13(0.62-2.06)$ & $0.65(0.35-1.20$ \\
\hline $50,000-69,999$ & $1.38(0.71-2.68)$ & $0.51(0.24-1.06$ \\
\hline$\geq 70,000$ & $1.60(0.89-2.87)$ & $0.70(0.38-1.31$ \\
\hline \multicolumn{3}{|l|}{ Employment status } \\
\hline Unemployed & 1 [Reference] & 1 [Reference \\
\hline Employed & $0.95(0.61-1.50)$ & $1.16(0.73-1.84$ \\
\hline \multicolumn{3}{|l|}{ Public transportation use, days/previous week } \\
\hline 0 & 1 [Reference] & 1 [Reference \\
\hline $1-4$ & $2.11(1.31-3.40)$ & $2.08(1.27-3.42$ \\
\hline$\geq 5$ & $3.47(1.47-8.19)$ & $8.61(3.87-19.20$ \\
\hline
\end{tabular}

Abbreviations: OR, odds ratio; $\mathrm{CI}$, confidence interval

Table 3. Relationship of Personal Characteristics and Perceived Environmental Factors to Public Transportation Use Among Adults ( $\mathrm{N}=$ 772 ) in St. Louis, Missouri

\begin{tabular}{|l|r|r|}
\hline \multirow{2}{*}{ Personal Characteristics and Perceived Environmental Factors } & \multicolumn{2}{|c|}{ Public Transportation Use } \\
\cline { 2 - 3 } Personal characteristics & $\mathbf{1 - 4}$ Days/Week & $\mathbf{2 5}$ Days/Week \\
\cline { 2 - 3 } Sex & OR (95\% CI) & \multicolumn{1}{|c|}{ OR (95\% CI) } \\
\hline Male & 1 [Reference] & \multicolumn{2}{|}{1 [Reference] } \\
\hline Female & $1.21(0.81-1.83)$ & $1.23(0.71-2.14)$ \\
\hline Age, $\mathbf{Y}$ & \multicolumn{2}{|}{} \\
\hline $18-29$ & $1[$ [Reference] & $1[$ Reference] \\
\hline $30-39$ & $1.00(0.53-1.90)$ & $0.95(0.43-2.08)$ \\
\hline $40-49$ & $1.34(0.90-2.56)$ & $0.93(0.41-2.13)$ \\
\hline $50-59$ & $1.98(1.06-3.70)$ & $1.69(0.80-3.57)$ \\
\hline$\geq 60$ & $0.86(0.45-1.62)$ & $0.34(0.14-0.86)$ \\
\hline Income, \$ & \\
\hline
\end{tabular}




\begin{tabular}{|c|c|c|}
\hline \multirow[b]{3}{*}{ Personal Characteristics and Perceived Environmental Factors } & \multicolumn{2}{|c|}{ Public Transportation Use } \\
\hline & 1-4 Days/Week & $\geq 5$ Days/Week \\
\hline & OR (95\% CI) & OR ( $95 \% \mathrm{CI})$ \\
\hline$<10,000$ & 1 [Reference] & 1 [Reference] \\
\hline $10,000-29,999$ & $0.56(0.35-0.92)$ & $0.84(0.45-1.57)$ \\
\hline $30,000-49,999$ & $0.27(0.13-0.51)$ & $0.49(0.23-1.03)$ \\
\hline $50,000-69,999$ & $0.28(0.13-0.58)$ & $0.51(0.21-1.20)$ \\
\hline$\geq 70,000$ & $0.40(0.24-0.70)$ & $0.10(0.03-0.34)$ \\
\hline \multicolumn{3}{|l|}{ Employment status } \\
\hline Unemployed & 1 [Reference] & 1 [Reference] \\
\hline Employed & $0.56(0.35-0.92)$ & $2.99(1.52-5.90)$ \\
\hline \multicolumn{3}{|l|}{ Perceived environmental factors } \\
\hline \multicolumn{3}{|l|}{ Speed of traffic } \\
\hline Disagree & 1 [Reference] & 1 [Reference] \\
\hline Agree & $0.54(0.36-0.81)$ & $0.76(0.44-1.32)$ \\
\hline \multicolumn{3}{|l|}{ Perceived nearby crime } \\
\hline Disagree & 1 [Reference] & 1 [Reference] \\
\hline Agree & $1.06(0.67-1.69)$ & $0.50(0.28-0.87)$ \\
\hline \multicolumn{3}{|l|}{ Safety from crime when walking during the day } \\
\hline Disagree & 1 [Reference] & 1 [Reference] \\
\hline Agree & $1.15(0.73-1.82)$ & $0.77(0.41-1.43)$ \\
\hline \multicolumn{3}{|l|}{ Safety from crime when walking at night } \\
\hline Disagree & 1 [Reference] & 1 [Reference] \\
\hline Agree & $0.91(0.53-1.58)$ & $0.59(0.29-1.18)$ \\
\hline \multicolumn{3}{|l|}{ Accessibility to sidewalks } \\
\hline Disagree & 1 [Reference] & 1 [Reference] \\
\hline Agree & $0.59(0.30-1.16)$ & $3.00(0.69-13.12)$ \\
\hline \multicolumn{3}{|l|}{ Number of destinations within a $10-\mathrm{min}$ walk } \\
\hline 0 & 1 [Reference] & 1 [Reference] \\
\hline $1-5$ & $1.52(0.72-3.23)$ & $2.86(0.78-10.49)$ \\
\hline $6-10$ & $1.37(0.61-3.10)$ & $2.22(0.57-8.60)$ \\
\hline$\geq 11$ & $0.74(0.30-1.81)$ & $1.50(0.36-6.30)$ \\
\hline
\end{tabular}

Abbreviations: OR, odds ratio; CI, confidence interval.

The opinions expressed by authors contributing to this journal do not necessarily reflect the opinions of the U.S.

Department of Health and Human Services, the Public Health Service, the Centers for Disease Control and Prevention, or the authors' affiliated institutions.

For Questions About This Article Contact pcdeditor@cdc.gov

Page last reviewed: July 03, 2014

Page last updated: July 03, 2014

Content source: National Center for Chronic Disease Prevention and Health Promotion 
Preventing Chronic Disease | Correlates of Walking for Transportation and Use of Publ... Page 10 of 10

Centers for Disease Control and Prevention 1600 Clifton Rd. Atlanta, GA 30333, USA

80o-CDC-INFO (80o-232-4636) TTY: (888) 232-6348 - Contact CDC-INFO

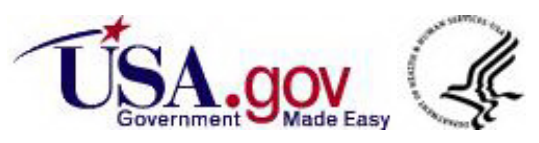

